\title{
"Awake" extracorporeal membrane oxygenation (ECMO): pathophysiology, technical considerations, and clinical pioneering
}

\author{
Thomas Langer ${ }^{1 *}$, Alessandro Santini ${ }^{1}$, Nicola Bottino ${ }^{1}$, Stefania Crotti ${ }^{1}$, Andriy I. Batchinsky ${ }^{2,3}$, \\ Antonio Pesenti ${ }^{1,4}$ and Luciano Gattinoni $i^{1,4}$
}

\begin{abstract}
Venovenous extracorporeal membrane oxygenation (vv-ECMO) has been classically employed as a rescue therapy for patients with respiratory failure not treatable with conventional mechanical ventilation alone. In recent years, however, the timing of ECMO initiation has been readdressed and ECMO is often started earlier in the time course of respiratory failure. Furthermore, some centers are starting to use ECMO as a first line of treatment, i.e., as an alternative to invasive mechanical ventilation in awake, non-intubated, spontaneously breathing patients with respiratory failure ("awake" ECMO). There is a strong rationale for this type of respiratory support as it avoids several side effects related to sedation, intubation, and mechanical ventilation. However, the complexity of the patient-ECMO interactions, the difficulties related to respiratory monitoring, and the management of an awake patient on extracorporeal support together pose a major challenge for the intensive care unit staff. Here, we review the use of vv-ECMO in awake, spontaneously breathing patients with respiratory failure, highlighting the pros and cons of this approach, analyzing the pathophysiology of patient-ECMO interactions, detailing some of the technical aspects, and summarizing the initial clinical experience gained over the past years.
\end{abstract}

\section{Background}

Venovenous extracorporeal membrane oxygenation (vv-ECMO) has been classically employed as a rescue therapy for patients with respiratory failure not treatable with conventional mechanical ventilation alone $[1,2]$. In recent years, however, ECMO is often started earlier in the time course of the acute respiratory distress syndrome (ARDS) in order to avoid possible detrimental effects of mechanical ventilation, such as ventilatorinduced lung injury [3-5]. It might be of interest to underline that, in the mechanically ventilated patient on ECMO, two lungs are contributing to respiration: the membrane lung, which is extremely efficient, and the native, failing lung, which can contribute only partially to gas exchange.

\footnotetext{
* Correspondence: tom.langer@hotmail.it

'Dipartimento di Anestesia, Rianimazione ed Emergenza Urgenza,

Fondazione IRCCS Ca' Granda-Ospedale Maggiore Policlinico, Via F. Sforza 35, 20122 Milan, Italy

Full list of author information is available at the end of the article
}

For this reason, some centers are pursuing the idea of using ECMO as a first line treatment, i.e., as an alternative to invasive mechanical ventilation in awake, non-intubated, spontaneously breathing patients with respiratory failure ("awake" ECMO). On one hand, this type of approach has several advantages as it could avoid mechanical ventilationassociated side effects; on the other, of course, its application is associated with several challenges.

In the present review we summarize the current knowledge on and initial experience with the use of vv-ECMO in awake, spontaneously breathing patients with respiratory failure.

\section{Pros and cons of spontaneous breathing}

Breathing is an active task in any surface-living animal with lungs and in all marine mammals. "Spontaneous" was an unnecessary adjective to the word "breathing" until the era of mechanical ventilation began. Since then, controversies have arisen regarding the advantages and 
disadvantages of maintaining spontaneous breathing in critically ill patients with respiratory failure [6, 7], whose treatment mainstay is still invasive mechanical ventilation.

In this section we summarize the possible advantages (pros) and disadvantages (cons) of spontaneous breathing.

\section{Pros}

1. Spontaneously breathing patients preferentially move the dorsal, more compliant part of their diaphragm. Ventilation is therefore directed towards the most dependent and better perfused parts of the lung, leading to optimal ventilation-perfusion matching [7]. In contrast, the shape of the diaphragm is altered in the sedated, paralyzed, mechanically ventilated patient [8], leading to a preferential passive movement of the paralyzed diaphragm and ventilation of the non-dependent lung. This worsens ventilation-perfusion matching during mechanical ventilation (Fig. 1).

2. The tone of the respiratory muscles in the awake, spontaneously breathing subject guarantees the expansion of the chest wall and lungs at end expiration (functional residual capacity). In contrast, anesthesia (with or without paralysis) leads to loss of muscle tone, inward displacement of the ribcage [9], and decreased functional residual capacity [10], which, in turn, can favor the formation of atelectasis. Of note, this mechanism is more pronounced in edematous, "heavy", ARDS lungs [11].

3. Maintaining diaphragmatic contraction and avoiding controlled mechanical ventilation could prevent ventilator-induced diaphragm dysfunction [12].

4. During spontaneous breathing, air moves from the mouth to the alveoli through a decrease in intrathoracic pressure, which favors venous return from extra-thoracic organs, maintaining cardiac filling and output. The same mechanism seems implicated in favoring pulmonary lymphatic drainage [13]. On the other hand, with mechanical ventilation the intrathoracic pressure increases during inspiration, having the opposite effect of reducing venous return, cardiac output, and thoracic lymph flow [13, 14].

5. The avoidance of endotracheal intubation could reduce the incidence of ventilator/intubationassociated pneumonia through the maintenance of the natural barrier defenses against bacteria [15].

\section{Cons}

1. Transpulmonary pressure is one of the forces implicated in the development of ventilator-induced

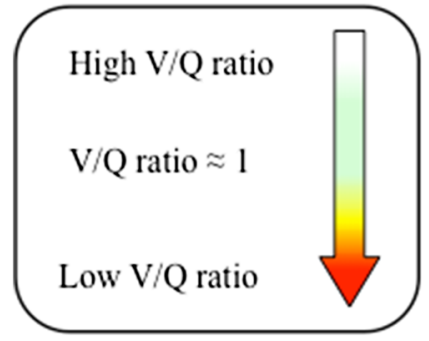

\section{a}

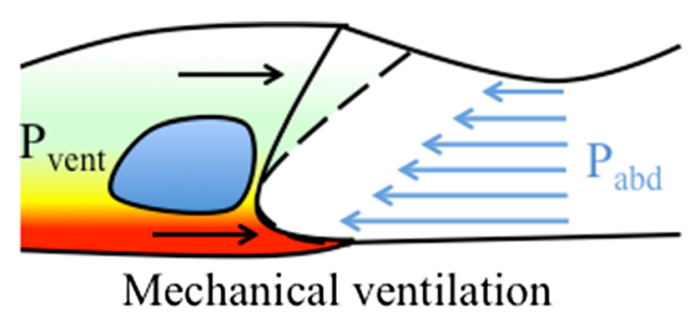

b

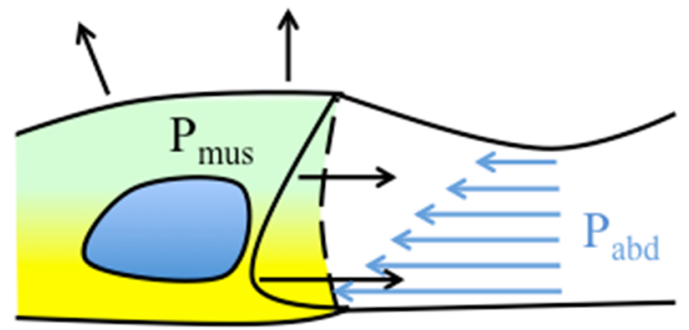

Spontaneous breathing

Fig. 1 Diaphragm motion and ventilation/perfusion distribution in the awake and in the anesthetized subject. The lung ventilation-to-perfusion ratio $(V / Q)$ is color-coded from white (high $V / Q$ ), to green $(\mathrm{V} / \mathrm{Q} \approx 1$ ), to red (low $\mathrm{V} / \mathrm{Q})$. Diaphragm shape at end expiration (continuous line) and end inspiration (dashed line) in the supine position is shown. Intra-abdominal pressure increases in the ventro-dorsal direction due to gravity (blue arrows) and displaces the dorsal part of the diaphragm more cephalad than the ventral part at end expiration. During mechanical ventilation the pressure applied by the mechanical ventilator displaces the ventral part of the diaphragm, which faces less intra-abdominal pressure, more than the dorsal part (passive movement). Ventilation will thus be distributed preferentially to the ventral lung regions, increasing the ventilation-to-perfusion ratio (V/Q) of these areas. In contrast, dorsal lung regions will receive less ventilation and their $V / Q$ will be lower (a). During spontaneous breathing (either assisted or unassisted), both the ventral and the dorsal part of the diaphragm move (active contraction). Ventilation will distribute more homogeneously along the ventro-dorsal axis of the lung and will more closely match perfusion $(V / Q \approx 1)(\mathbf{b})$ 
lung injury [16-18]. Spontaneous breathing generates positive transpulmonary pressure (airway pressure minus pleural pressure) similarly to mechanical ventilation. Lung damage might therefore also derive from spontaneous hyperventilation (spontaneous ventilation-induced lung injury) [19-22].

2. When the work of breathing is very high, the strenuous respiratory muscle effort can lead to high oxygen $\left(\mathrm{O}_{2}\right)$ consumption (and carbon dioxide $\left(\mathrm{CO}_{2}\right)$ production), i.e., a high cost of breathing, which in turn could worsen hypoxemia. If gas exchange needs are not met in other ways (e.g., through extracorporeal respiratory support), sedation, intubation, and mechanical ventilation could be necessary to avoid muscle exhaustion.

3. Emergent intubation and initiation of mechanical ventilation might become necessary in the awake, spontaneously breathing, non-intubated patient in cases of ECMO equipment failure.

\section{Pros and cons of keeping patients awake}

Managing awake patients is a relatively new and challenging task in medical intensive care units (ICU).

Pros

1. Reduction of delirium: the pathogenesis of delirium in the ICU is multifactorial, one of the main determinants being the use of sedative drugs [23]. Avoiding or reducing the amount of hypnotic agents could therefore reduce the development of this disturbance, which is associated with prolonged ICU/hospital stay and mortality [24].

2. Rehabilitation: muscle mass loss and critical illness myopathy and polyneuropathy often affect ICU patients [25]. Awake patients can actively collaborate with physiotherapists to perform physical rehabilitation, therefore reducing the incidence of these neuromuscular disorders [26]. The organizational effort needed to safely perform physical therapy in ECMO patients needs to be considered. In our experience the multidisciplinary team includes two physical therapists, two nurses, and a physician.

3. Interaction with relatives/friends and medical staff: patient-relative interactions comprise one of the most striking differences between the ICU and other hospital wards. The ability of an awake patient to communicate with friends and relatives could render the unfriendly ICU environment a more usual and easy to cope with situation for both patient and visitors. Furthermore, it is possible for an awake patient to communicate her/his symptoms and needs to the medical staff, something that is heavily underappreciated and yet is a fundamental source of information about the patient's condition and response to therapy.

\section{Cons}

1. Risk of invasive device displacement: awake patients must be carefully monitored and instructed not to remove any invasive device to avoid the risk of selfharm. This is of particular relevance for patients on ECMO.

2. Patient discomfort, pain and anxiety: an awake patient requires analgesics for invasive device tolerance and pain control (e.g., movements during physiotherapy, invasive procedures). Furthermore, the ICU can be a very stressful environment because of the procedures/actions undertaken on the awake patient as well as those on other patients. Depending on the organization of the ICU (single room versus open-plan), supplemental care is required with regard to what is said and done in the proximity of an awake patient.

\section{Physiology and pathophysiology of the control of breathing}

In normal physiology, spontaneous breathing is largely controlled by the $\mathrm{PCO}_{2}$ (partial pressure of carbon dioxide; and therefore $\mathrm{pH}$ ) and $\mathrm{O}_{2}$. On one hand, the hypoxic ventilatory response is activated only at low levels of $\mathrm{PO}_{2}$ (partial pressure of oxygen; $40-50 \mathrm{mmHg}$ ) and is, therefore, rarely the primary respiratory drive [27]. On the other hand, the key role of $\mathrm{CO}_{2}$ as a trigger for respiration has been clearly identified, including through experiments performed with the use of extracorporeal gas exchange $[28,29]$. Our knowledge on the control of breathing is, however, largely limited to studies performed on healthy animals and humans. In conditions of acute lung disease, lung receptors that are silent in normal physiological conditions might be activated and could play a role in determining the respiratory pattern of these patients [30]. Interestingly, typical features of lung disease, such as systemic and local pulmonary inflammation [29, 31-33], lung collapse, and lung microembolism [34], have been shown to activate these receptors.

\section{Physiology and pathophysiology of spontaneous breathing}

Breathing is a complex function that has the ultimate purpose of delivering oxygen to every cell of the organism in order to perform cell respiration, i.e., the production of energy from the oxidation of a substrate in the presence of an acceptor of electrons-oxygen. The other purpose of breathing is the clearance of the waste product of cellular respiration, namely carbon dioxide. 
Schematically, the respiratory system is composed of a pump - the respiratory muscles - and a gas exchanger - the lungs. The pump provides the force needed to expand the ribcage and lungs, while the coupling between these two structures is provided by the pleura. During spontaneous inspiration the ribcage expands and the diaphragm is displaced in the caudal direction. The resultant decrease in pleural pressure decreases the alveolar pressure to subatmospheric levels and, due to this pressure gradient, air reaches the alveoli through the tracheo-bronchial tree. Here, gases are passively transferred to and from blood according to their partial pressure gradients.

The simplified equation of motion (Eq. 1) describes the force that must be exerted by the respiratory muscles in order to move air from the atmosphere to the lungs:

$$
\mathrm{P}_{\text {mus }}=\mathrm{V} * \mathrm{E}+. \mathrm{V} * \mathrm{R}
$$

where $\mathrm{P}_{\text {mus }}$ represents the pressure exerted by the respiratory muscles, $\mathrm{E}$ and $\mathrm{R}$ the respiratory system elastance and resistance, respectively, and $\mathrm{V}$ and $\dot{\mathrm{V}}$ the volume and flow, respectively, of gas entering the respiratory system.

During the healthy state, increases in respiratory muscular effort are usually due to increased $\mathrm{CO}_{2}$ production, e.g., during exercise, with consequently increased ventilation $(\mathrm{V}$ and $\dot{\mathrm{V}})$ at fairly constant mechanical characteristics of the lung ( $\mathrm{E}$ and $\mathrm{R})$. In patients with acute lung injury, $\mathrm{E}$ is typically worsened due to the accumulation of edema, which causes a reduction in ventilatable lung volume [11]. Furthermore, airway hyperreactivity and inflammation may lead to an increase in $\mathrm{R}$ in ARDS patients [35]. Finally, due to the presence of a high dead space fraction [36], an increased minute ventilation is needed in order to remove the metabolically produced $\mathrm{CO}_{2}$. The combination of these factors results in the need for greatly increased muscular effort $\left(\mathrm{P}_{\text {mus }}\right)$ to satisfy the gas exchange needs. Of note, the increased work of breathing increases oxygen consumption and $\mathrm{CO}_{2}$ production by the respiratory muscles, potentially leading to a vicious cycle which accelerates the process of muscular exhaustion.

Available therapeutic options operate on very different concepts. On the one hand, therapy aims at improving lung function ( $\mathrm{E}$ and $\mathrm{R}$ ) through different pharmacological interventions, e.g., inhaled bronchodilators or antibiotics. On the other, time is needed for such therapy to be effective and, therefore, supportive therapy of the failing respiratory system is required. During controlled mechanical ventilation the pressure generated by the ventilator $\left(\mathrm{P}_{\text {vent }}\right)$ replaces $\mathrm{P}_{\text {mus }}$, therefore acting on the left side of Eq. 1. This type of intervention has a straightforward application during respiratory failure due to neuromuscular diseases, such as amyotrophic lateral sclerosis, poliomyelitis, and others, or during general anesthesia where muscular function is pharmacologically abolished.

In contrast, $\mathrm{vv}$-ECMO acts on the right side of Eq. 1, lowering the need to breath $(\mathrm{V}$ and $\dot{\mathrm{V}})$, by replacing the gas exchange function of the lung $\left(\mathrm{CO}_{2}\right.$ removal and blood oxygenation). Of note, this type of intervention would be the logical approach in cases of respiratory failure due to lung disease, i.e., conditions in which the respiratory muscles are unaffected by the disease and the lung function is impaired.

\section{Technical considerations}

\section{Cannulation approaches}

Venous cannulation for vv-ECMO is preferentially performed percutaneously using the Seldinger technique [37] and may involve two different approaches: (i) single site cannulation using bicaval dual-lumen catheters; or (ii) dual site cannulation (femoro-jugular or femorofemoral). Advantages of single site, bicaval dual-lumen cannulae include freeing up the femoral veins, thus favoring passive and active physical therapy [38], and reduced risk of catheter-related infection and insertion site bleeding [39]. The catheters used in adults range between 27 and $31 \mathrm{Fr}$ (9-10.3 mm diameter), i.e., substantially larger diameters are needed compared with dual site catheters (between 19 and $25 \mathrm{Fr}$ ) in order to guarantee sufficient blood flows through the membrane lung [40]. Positioning bicaval dual-lumen catheters is a major challenge and fluoroscopy and/or transesophageal echocardiography are usually needed to guarantee the correct placement [41-43]. Of note, both ventricular rupture during placement and displacement of the cannula into the right ventricle or hepatic veins during ECMO support, with consequent inadequate ECMO blood flow and reduced respiratory support, have been described [44, 45]. As cannula displacement could be related to activity/agitation of patients, the use of bicaval dual-lumen cannulae should be done with caution in potentially agitated patients or patients with extremely severe respiratory failure. Due to the complexity and associated risks, patients are usually anesthetized and intubated for the placement of bicaval dual-lumen cannulae. In contrast, when using the dual site approach, cannulation may also be performed in awake, spontaneously breathing patients under light sedation and local anesthesia. However, at least one cannula needs to be placed at the groin, i.e., in the femoral vein, resulting in limited possibility to perform physical therapy.

\section{Physiology of extracorporeal gas exchange and patient-machine interactions}

The physiological rules regulating pulmonary gas exchange also apply to extracorporeal gas exchange. Indeed, $\mathrm{CO}_{2}$ removal depends primarily on ventilation of the membrane lung, i.e., on sweep gas flow, and, to a lesser extent, 
on the $\mathrm{PCO}_{2}$ of blood entering the ECMO system. Furthermore, $\mathrm{CO}_{2}$ removal depends, in a logarithmic relationship, on the blood flow through the membrane lung [28].

The major determinants of oxygen transfer are the extracorporeal blood flow and the hemoglobin saturation of blood entering the membrane lung [46], given that blood oxygenation is a saturable process. Of note, metabolically produced $\mathrm{CO}_{2}$ (approximately $200 \mathrm{ml} / \mathrm{min}$ ) can, in theory, be cleared from a low quantity of venous blood (0.5-1 L), while significantly higher blood volumes are required in order to provide an equivalent amount of oxygen.

The awake, spontaneously breathing patient is an independent and unpredictable variable with potentially relevant implications for patient-machine interactions. Indeed, the maximum blood flow through the ECMO system depends on not only the size of the cannula, as mentioned above, but also the adequacy of the central volume status, i.e., preload and venous return. The volume status is influenced by heart-lung interactions and, in spontaneously breathing patients, particularly by the periodic negative intrathoracic pressures caused by the activity of the respiratory muscles. During normal, physiological spontaneous breathing, pleural pressure swings are small, around $4-6 \mathrm{cmH}_{2} \mathrm{O}$ [47] and the hemodynamic effect is usually negligible. Nevertheless, during respiratory distress, pleural pressure swings can increase significantly (often reaching $20-30 \mathrm{cmH}_{2} \mathrm{O}$ ) and diaphragmatic excursions can be very pronounced, even during extracorporeal support (Fig. 2). This, in turn, can lead to a blood shift from the inferior to the superior vena cava and to a collapse of the inferior vena cava caused by increased abdominal pressure. The net result, in the case of blood drainage from the inferior vena cava, could be the collapse of the vein around the drainage cannula with subsequent reduction in blood flow (Fig. 3). Of note, bicaval dual-lumen catheters, which drain from both the intra- and extra-thoracic compartments, should be less affected by this kind of interaction.

Also, blood reinfusion (afterload) can become critical in the case of increased intrathoracic pressure, such as during coughing or Valsalva's maneuver, leading to relevant, though usually transient, reductions in blood flow.

In addition to mechanical patient-machine interactions linked to blood drainage and reinfusion, physiological and metabolic interactions caused by extracorporeal gas exchange also take place. Extracorporeal $\mathrm{CO}_{2}$ removal, the primary and most efficient effect of ECMO support, allows respiratory acidosis to be corrected when present, thus potentially reducing pulmonary vascular resistance and improving systemic hemodynamics [48]. The respiratory response to $\mathrm{CO}_{2}$ removal, initially observed in experimental studies, is to decrease minute ventilation, up to apnea,
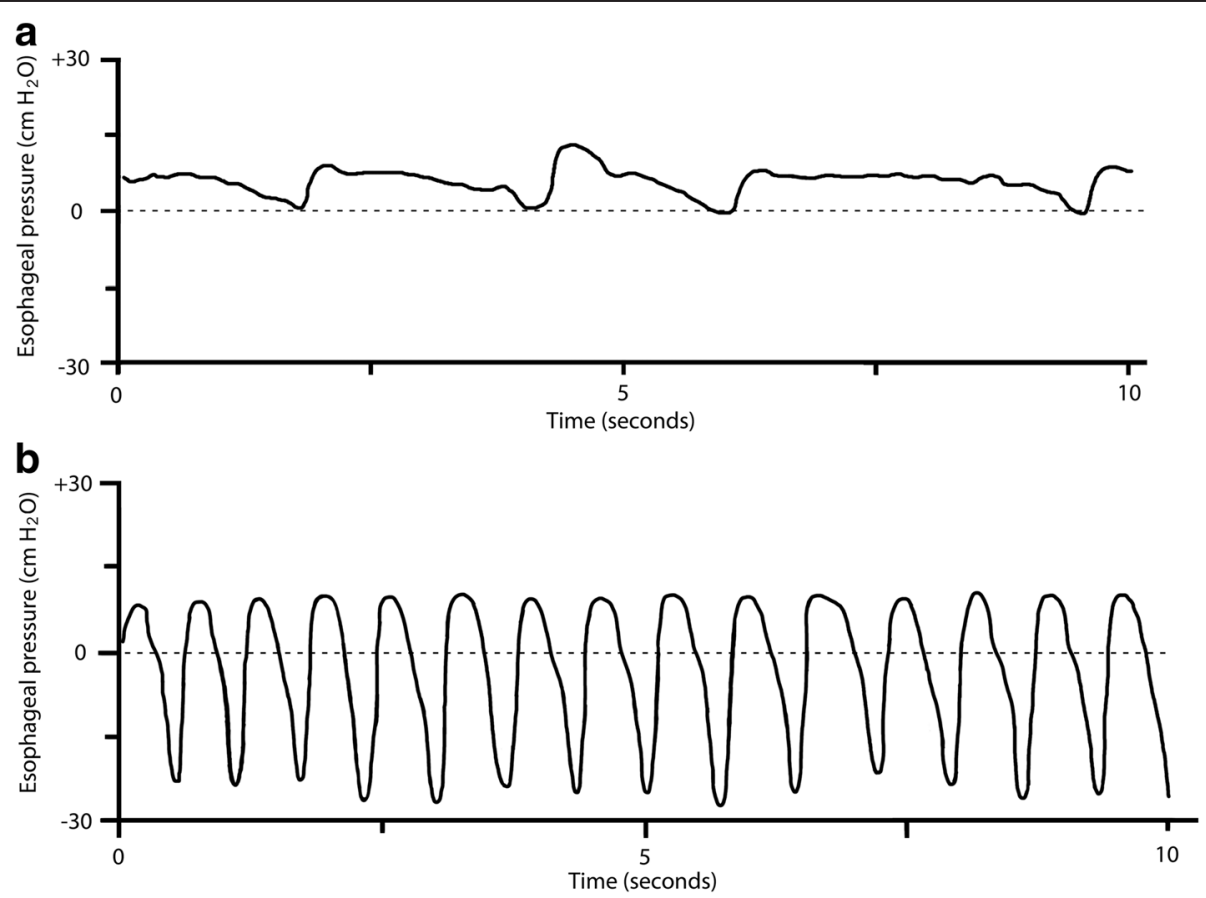

Fig. 2 Esophageal pressure swings during spontaneous breathing in normal conditions and with ARDS. a Esophageal pressure $\left(P_{\mathrm{es}}\right)$ trace of an awake, spontaneously breathing sheep with healthy lungs. Esophageal pressure swings $\left(\Delta \mathrm{P}_{\mathrm{es}}\right)$ are around $4-6 \mathrm{cmH}_{2} \mathrm{O}$ and the respiratory rate is around 14-18 breaths per minute. $\mathbf{b} \mathrm{P}_{\mathrm{es}}$ trace of an awake, spontaneously breathing sheep with oleic acid-induced ARDS. Measured $\triangle \mathrm{P}_{\mathrm{es}}$ values are around $20-30 \mathrm{cmH}_{2} \mathrm{O}$ and respiratory rate is greatly increased. Personal experimental data of Thomas Langer and Andriy Batchinsky [49] 


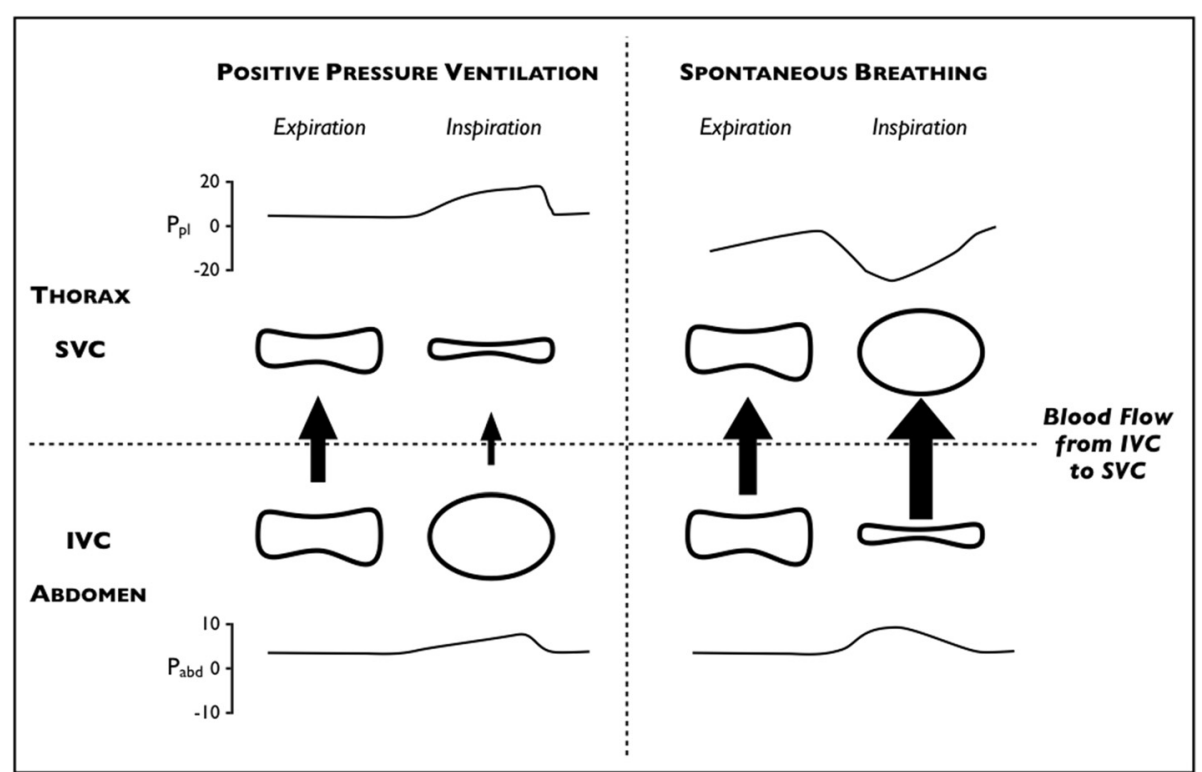

Fig. 3 Shape of the intra- and extrathoracic veins in different transmural pressure conditions (heart-lung interactions). Changes in pleural pressure $\left(P_{p l}\right)$, abdominal pressure $\left(P_{a b d}\right)$, the shape of the superior and inferior venae cavae (SVC and IVC, respectively), and the amount of blood flow (arrows) from the abdomen to the thorax during mechanical ventilation (left panel) and spontaneous breathing (right panel). During positive pressure ventilation, the increased pleural pressure squeezes the SVC and reduces blood flow from the abdominal compartment. This induces a distention of the IVC, favoring blood drainage to the extracorporeal circuit. During spontaneous breathing with high inspiratory effort, the significant decrease in pleural pressure dilates the SVC and increases blood flow from the abdominal compartment. This may induce a collapse of the IVC, hindering blood drainage to the extracorporeal circuit

when $100 \%$ of the metabolically produced $\mathrm{CO}_{2}$ is removed by the membrane lung $[28,49,50]$. This will reduce the work of the respiratory muscles, lowering the cost of breathing, which may be as high as $50 \%$ of total oxygen consumption in patients with respiratory failure $[49,51]$.

In clinics, it has been anecdotally observed that some ECMO patients respond physiologically, i.e., decrease their alveolar ventilation proportionally to the amount of $\mathrm{CO}_{2}$ removed extracorporeally, while others tend to vary their ventilation only slightly with variations of $\mathrm{CO}_{2}$ removal (manuscript submitted). Reasons for such differences are under investigation but hypotheses include the effect of agitation, discomfort, and cough and the involvement of mechanisms other than $\mathrm{pH} / \mathrm{PCO}_{2} / \mathrm{PO}_{2}$ in the control of breathing and dyspnea generation, e.g., activation of pulmonary receptors [30, 32, 52].

Of note, hypoventilation induced by extracorporeal $\mathrm{CO}_{2}$ removal will lower the global ventilation-to-perfusion ratio of the natural lung and could lead to reabsorption atelectasis, therefore worsening hypoxemia [53]. To avoid atelectasis it is useful to (i) titrate sweep gas flow in order to relieve dyspnea and avoid high pleural pressure swings, (ii) maintain a certain degree of spontaneous respiratory activity to avoid hypoventilation-related atelectasis, and (iii) increase mean airway pressure through the application of continuous positive airway pressure (CPAP) or noninvasive ventilation.
Increasing the supply of oxygen through the membrane lung, thus increasing arterial $\mathrm{PO}_{2}$, has a smaller effect on ventilation compared with $\mathrm{CO}_{2}$ removal, as the hypoxic respiratory drive is usually involved only at low $\mathrm{PO}_{2}$ values [27]. Nevertheless, it was demonstrated that increasing the inspiratory fraction of oxygen and therefore $\mathrm{PO}_{2}$ in hypoxic ARDS patients on pressure support ventilation (leaving all other parameters unchanged) caused a reduction in minute ventilation, mainly attributable to a reduced respiratory rate [54].

Finally, vv-ECMO increases venous oxygen saturation and venous oxygen tension and could, therefore, reduce hypoxic pulmonary vasoconstriction, having a twofold effect, (i) increasing the shunt fraction and (ii) reducing pulmonary arterial pressure, therefore indirectly unloading the right ventricle $[55,56]$.

\section{Monitoring during awake ECMO}

Hemodynamic monitoring in awake, spontaneously breathing patients on ECMO does not differ from the monitoring performed in sedated and intubated ECMO patients. Conversely, respiratory monitoring is a major challenge. Indeed, physicians are blinded to both airway pressures and tidal volumes, which are the mainstays of respiratory monitoring in ventilated patients.

Physicians need, therefore, to rely on the clinical evaluation of signs and symptoms of respiratory distress, 
such as respiratory rate, dyspnea, rapid shallow breathing, and others. In addition, some centers monitor esophageal pressure swings, i.e., a surrogate of variations in pleural pressure generated by the inspiratory muscles [57]. These pressure swings are evaluated in dynamic conditions and represent, therefore, the pressure applied to the alveoli to overcome both the elastic and resistive workload. The elastic component is the transpulmonary pressure producing alveolar inflation, while the resistive component generates flow through the airways. Of note, both components, i.e., transpulmonary pressures and negative inspiratory pressures due to resistive workload, could, in the case of very high values, worsen the underlying lung injury [58]. Therefore, from our point of view, and regardless of the cause of the increased esophageal swings, these need to be controlled in order to avoid additional pulmonary injury. Usually, reduction of high esophageal swings can be achieved by increasing the sweep gas flow, therefore increasing extracorporeal $\mathrm{CO}_{2}$ removal. If not sufficient, light sedation could help to slightly reduce the respiratory drive. At our institution, despite the lack of sound clinical evidence on the topic, if a patient's esophageal swings remain "dangerously" high $\left(>15 \mathrm{cmH}_{2} \mathrm{O}\right)$, patients are usually deeply sedated and switched to conventional invasive mechanical ventilation.

\section{Evaluation of gas exchange in the native lung}

Assessment of gas exchange in the native, diseased lung is extremely difficult in patients on vv-ECMO. Proper evaluation of the oxygenation capabilities of the native lung is hindered by the increased shunt fraction caused by the partial loss of pulmonary hypoxic vasoconstriction.

On the other side, evaluation of the $\mathrm{CO}_{2}$ clearing capabilities of the native lung is also challenging. At steady state, $\mathrm{CO}_{2}$ elimination $\left(\mathrm{VCO}_{2}\right)$ equals $\mathrm{CO}_{2}$ production. During extracorporeal $\mathrm{CO}_{2}$ removal total $\mathrm{VCO}_{2}$ equals extracorporeal $\left(\mathrm{V}_{\mathrm{M}} \mathrm{CO}_{2}\right)$ plus patient $\mathrm{CO}_{2}$ elimination
$\left(\mathrm{V}_{\mathrm{L}} \mathrm{CO}_{2}\right) \cdot \mathrm{V}_{\mathrm{M}} \mathrm{CO}_{2}$ can be easily measured by analyzing the composition of gas exiting the membrane lung and multiplying the $\mathrm{CO}_{2}$ concentration by the sweep gas flow. In contrast, measurement of $\mathrm{V}_{\mathrm{L}} \mathrm{CO}_{2}$ is difficult in non-intubated patients. Side-stream capnographs measuring end-tidal $\mathrm{CO}_{2}$ in spontaneously breathing patients are now available and allow estimation of the alveolar dead space fraction; however, they do not provide volumetric data and $\mathrm{V}_{\mathrm{L}} \mathrm{CO}_{2}$ cannot, therefore, be assessed.

Of note, the contribution of the membrane lung to gas exchange can be temporarily zeroed by interruption of the sweep gas (flow $=0 \mathrm{~L} / \mathrm{min}$ ) so that the performance of the native lung can be better evaluated. Nevertheless, this procedure is usually performed during evaluation of weaning from ECMO and rarely in patients requiring elevated extracorporeal support.

\section{Clinical pioneering \\ Bridge to lung transplantation}

The use of vv-ECMO in awake, non-intubated spontaneously breathing patients was first described for respiratory deterioration in patients awaiting lung transplantation (as a "bridge" to lung transplantation). These patients are the ideal candidates for an awake ECMO approach given their usual single organ dysfunction, their fragile heart-lung equilibrium, and the potential great benefit from the maintenance of preoperative physical rehabilitation $[59,60]$. Several case series have been published over the past years (Table 1) and, more recently, a retrospective analysis with historical controls showed a better survival in awake ECMO patients compared with those on mechanical ventilation [61].

Furthermore, a recent study showed that patients bridged with awake ECMO spent less post-operative time on mechanical ventilation and had shorter ICU and hospital lengths of stay compared with patients bridged with mechanical ventilation [62]. Nonetheless, patients who experience a rapid respiratory deterioration, and

Table 1 Studies on awake ECMO as a bridge to lung transplantation

\begin{tabular}{llllll}
\hline Reference & Year & Number of patients & Average bridge duration (days) & Type of extracorporeal support & Successful bridge \\
\hline Olsson et al. [72] & 2010 & 5 & 21 & VA & $4 / 5$ \\
Fuehner et al. [61] & 2012 & 26 & 9 & W, VA & NA \\
Javidfar et al. [73] & 2012 & 6 & NA & W, VA & NA \\
Hoopes et al. [74] & 2013 & 18 & 11 & W (10), VA (2) & $18 / 18$ \\
Crotti et al. [62] & 2013 & 10 & & PA-LA (2), RA-Ao (4) & W (8), VA (1), AV (1) \\
Lang et al. [75] & 2014 & 5 & 28 & AV (2), W (2) & $8 / 10$ \\
Mohite et al. [76] & 2015 & 7 & 21 & W, VA & NA \\
Inci et al. [77] & 2015 & 6 & 89 & NA & $6 / 6$ \\
\hline
\end{tabular}

Studies on awake ECMO as a bridge to lung transplantation reporting at least five patients are presented in chronological order of publication. "Successful bridge" defines the number of patients bridged with "awake ECMO" to lung transplantation without the need for intubation and mechanical ventilation

$A V$ arterio-venous, NA not available, PA-LA pulmonary artery-left atrium, RA-Ao right atrium-ascending aorta, $V A$ veno-arterial, $V V$ veno-venous 
Table 2 Studies on awake ECMO in COPD and ARDS patients

\begin{tabular}{|c|c|c|c|c|c|c|c|}
\hline Reference & Year & $\begin{array}{l}\text { Type of } \\
\text { disease }\end{array}$ & $\begin{array}{l}\text { Number of } \\
\text { patients }\end{array}$ & $\begin{array}{l}\text { Average support } \\
\text { duration (days) }\end{array}$ & $\begin{array}{l}\text { Type of extracorporeal } \\
\text { support }\end{array}$ & $\begin{array}{l}\text { Successful management } \\
\text { without IMV }\end{array}$ & $\begin{array}{l}\text { Successful weaning } \\
\text { from IMV }\end{array}$ \\
\hline $\begin{array}{l}\text { Kluge et al. } \\
\text { [68] }\end{array}$ & 2012 & COPD & 14 & 9 & PECLA & $13 / 14$ & NA \\
\hline $\begin{array}{l}\text { Burki et al. } \\
\text { [66] }\end{array}$ & 2013 & COPD & 20 & 4 & Low flow $\mathrm{ECCO}_{2} \mathrm{R}$ & $9 / 9^{*}$ & $3 / 11^{\S}$ \\
\hline $\begin{array}{l}\text { Abrams et al. } \\
\text { [65] }\end{array}$ & 2013 & COPD & 5 & 8 & Low flow $\mathrm{ECCO}_{2} \mathrm{R}$ & NA & 5 \\
\hline $\begin{array}{l}\text { Del Sorbo et } \\
\text { al. [67] }\end{array}$ & 2015 & COPD & 25 & 2 & Low flow $\mathrm{ECCO}_{2} \mathrm{R}$ & $22 / 25$ & NA \\
\hline $\begin{array}{l}\text { Hoeper et al. } \\
{[70]}\end{array}$ & 2013 & ARDS & 6 & 10 & W & $3 / 6$ & NA \\
\hline
\end{tabular}

Studies on awake ECMO for acute exacerbation of COPD or ARDS reporting at least five patients are presented in chronological order of publication and according to type of disease. "Successful management without IMV" defines the number of patients managed without invasive mechanical ventilation during the ICU stay. "Successful weaning from IMV" defines the number of patients already intubated, mechanically ventilated, and on ECMO who were weaned from invasive mechanical ventilation, extubated, and managed with awake ECMO. ${ }^{*}$ Patients of groups 1 and 2 and ${ }^{\S}$ patients of group 3 of the original publication by Burki et al.

$A R D S$ acute respiratory distress syndrome, $C O P D$ chronic obstructive pulmonary disease, $E C C \mathrm{O}_{2} R$ extra-corporeal $\mathrm{CO}_{2}$ removal, IMV invasive mechanical ventilation, $N A$ not available, PECLA pumpless extra-corporal lung assist; $W$ veno-venous

therefore need preoperative invasive respiratory support (mechanical ventilation and/or ECMO), apparently have a higher postoperative risk of death compared with patients not requiring preoperative invasive respiratory support [63]. These findings suggest that the condition of preoperative patients has a higher impact on postoperative outcome than the type of respiratory support.

\section{Exacerbation of chronic obstructive pulmonary disease}

Carbon dioxide retention, caused by dynamic hyperinflation, ventilation/perfusion mismatch, and reduction of alveolar ventilation, is a typical feature of acute exacerbation of chronic obstructive pulmonary disease (COPD). In the case of failed medical therapy and non-invasive ventilation, intubation and invasive mechanical ventilation might become necessary [64], exposing these patients to several mechanical ventilation-associated side effects.

Since COPD patients are usually characterized by hypercapnia and only mild hypoxemia, low blood flow extracorporeal $\mathrm{CO}_{2}$ removal systems could be sufficient to unload their respiratory system. Pioneering studies on the topic described a reduced intubation rate in acute exacerbations of COPD patients failing non-invasive ventilation and supported with extracorporeal gas exchange (Table 2) [65-68]. Furthermore, some authors described the possibility, through the use of extracorporeal $\mathrm{CO}_{2}$ removal, to facilitate extubation and perform physical therapy in COPD patients already supported with mechanical ventilation [65, 69]. Despite the lack of sound clinical evidence, this strategy seems to be promising given the known drawbacks of mechanical ventilation in this category of patients.

\section{Acute respiratory distress syndrome}

Recently, some groups have explored the possibility of using ECMO as an alternative to mechanical ventilation also in awake, spontaneously breathing ARDS patients $[70,71]$. Available data are very scarce; nevertheless, patients of this sort with respiratory failure appear to be more complicated to treat with an awake ECMO approach given their frequent multiple organ dysfunction.

\section{Conclusions}

There is a strong rationale for the use of vv-ECMO in the treatment of respiratory failure in awake, spontaneously breathing patients (awake ECMO) as it allows several side effects related to sedation, intubation, and mechanical ventilation to be avoided. However, the complexity of the heart-lung-ECMO system interactions and the difficulties related to respiratory monitoring and the management of an awake patient on extracorporeal support make the awake ECMO patient a major challenge for the ICU staff. At the time of writing, sound clinical data on the topic are scarce and future clinical studies are needed in order to improve our understanding of the pathophysiology of awake ECMO patients and to evaluate any possible outcome benefit compared with the current standard of care.

\footnotetext{
Abbreviations

ARDS: acute respiratory distress syndrome; COPD: chronic obstructive pulmonary disease; E: respiratory system elastance; ECMO: extracorporeal membrane oxygenation; ICU: intensive care unit; $\mathrm{PCO}_{2}$ : partial pressure of carbon dioxide; $P_{\text {mus }}$ : pressure generated by the respiratory muscles; $\mathrm{PO}_{2}$ : partial pressure of oxygen; $P_{\text {vent }}$ : pressure generated by the mechanical ventilator; $R$ : respiratory system resistance; $V$ : volume of gas entering the respiratory system; $\dot{\mathrm{V}}$ : flow air gas entering the respiratory system; $\mathrm{VCO}_{2}$ : total carbon dioxide elimination; $\mathrm{V}_{1} \mathrm{CO}_{2}$ : carbon dioxide elimination through the native lung; $\mathrm{V}_{\mathrm{M}} \mathrm{CO}_{2}$ : carbon dioxide elimination through the membrane lung; vv-ECMO: venovenous extracorporeal membrane oxygenation.
}

Competing interests

The authors declare that they have no competing interests. 


\section{Authors' contributions}

All authors contributed to the literature review and manuscript preparation and approved the final draft.

\section{Acknowledgements}

We are grateful to George Harea and Dr. Eleonora Carlesso for graphical assistance. The review was supported by institutional funds only.

\section{Author details}

'Dipartimento di Anestesia, Rianimazione ed Emergenza Urgenza, Fondazione IRCCS Ca' Granda-Ospedale Maggiore Policlinico, Via F. Sforza 35, 20122 Milan, Italy. ${ }^{2}$ The Geneva Foundation, Tacoma, WA, USA. ${ }^{3}$ Multi Organ Support and Preservation Task Area, U.S. Army Institute of Surgical Research (USAISR), Ft. Sam Houston, Texas, USA. ${ }^{4}$ Dipartimento di Fisiopatologia Medico-Chirurgica e dei Trapianti, Università degli Studi di Milano, Milan, Italy.

\section{Received: 19 January 2016 Accepted: 27 April 2016}

\section{Published online: 30 June 2016}

\section{References}

1. Gattinoni L, Pesenti A, Mascheroni D, Marcolin R, Fumagalli R, Rossi F, et al. Low-frequency positive-pressure ventilation with extracorporeal $\mathrm{CO}_{2}$ removal in severe acute respiratory failure. JAMA. 1986;256:881-6.

2. Morris AH, Wallace CJ, Menlove RL, Clemmer TP, Orme Jr JF, Weaver LK, et al. Randomized clinical trial of pressure-controlled inverse ratio ventilation and extracorporeal $\mathrm{CO} 2$ removal for adult respiratory distress syndrome. Am J Respir Crit Care Med. 1994;149:295-305.

3. Davies A, Jones D, Bailey M, Beca J, Bellomo R, Blackwell N, et al. Extracorporeal membrane oxygenation for 2009 influenza A (H1N1) acute respiratory distress syndrome. JAMA. 2009;2009(302):1888-95.

4. Gattinoni L, Carlesso E, Langer T. Extracorporeal membrane oxygenation. Crit Care. 2011;15:243.

5. Peek GJ, Mugford M, Tiruvoipati R, Wilson A, Allen E, Thalanany MM, et al. Efficacy and economic assessment of conventional ventilatory support versus extracorporeal membrane oxygenation for severe adult respiratory failure (CESAR): a multicentre randomised controlled trial. Lancet. 2009;374 1351-63.

6. Putensen C, Mutz NJ, Putensen-Himmer G, Zinserling J. Spontaneous breathing during ventilatory support improves ventilation-perfusion distributions in patients with acute respiratory distress syndrome. Am J Respir Crit Care Med. 1999;159:1241-8.

7. Wrigge H, Zinserling J, Neumann P, Defosse J, Magnusson A, Putensen C, et al. Spontaneous breathing improves lung aeration in oleic acid-induced lung injury. Anesthesiology. 2003;99:376-84.

8. Froese $A B$, Bryan $A C$. Effects of anesthesia and paralysis on diaphragmatic mechanics in man. Anesthesiology. 1974;41:242-55.

9. Warner DO, Warner MA, Ritman EL. Human chest wall function while awake and during halothane anesthesia. I. Quiet breathing. Anesthesiology. 1995; 82:6-19.

10. Hedenstierna G, Strandberg A, Brismar B, Lundquist H, Svensson L, Tokics L. Functional residual capacity, thoracoabdominal dimensions, and central blood volume during general anesthesia with muscle paralysis and mechanical ventilation. Anesthesiology. 1985;62:247-54.

11. Gattinoni L, Pesenti A. The concept of "baby lung". Intensive Care Med. 2005;31:776-84.

12. Vassilakopoulos T, Petrof BJ. Ventilator-induced diaphragmatic dysfunction Am J Respir Crit Care Med. 2004;169:336-41.

13. Frostell C, Blomqvist H, Hedenstierna G, Halbig I, Pieper R. Thoracic and abdominal lymph drainage in relation to mechanical ventilation and PEEP. Acta Anaesthesiol Scand. 1987;31:405-12.

14. Funk DJ, Jacobsohn E, Kumar A. Role of the venous return in critical illness and shock: part II-shock and mechanical ventilation. Crit Care Med. 2013;41:573-9.

15. Hunter JD. Ventilator associated pneumonia. BMJ. 2012;344, e3325.

16. Caironi P, Langer T, Carlesso E, Protti A, Gattinoni L. Time to generate ventilator-induced lung injury among mammals with healthy lungs: a unifying hypothesis. Intensive Care Med. 2011:37:1913-20.

17. Chiumello D, Carlesso E, Cadringher P, Caironi P, Valenza F, Polli F, et al. Lung stress and strain during mechanical ventilation for acute respiratory distress syndrome. Am J Respir Crit Care Med. 2008;178:346-55.
18. Protti A, Cressoni M, Santini A, Langer T, Mietto C, Febres D, et al. Lung stress and strain during mechanical ventilation: any safe threshold? Am J Respir Crit Care Med. 2011;183:1354-62.

19. Hopkins SR, Schoene RB, Henderson WR, Spragg RG, Martin TR, West JB. Intense exercise impairs the integrity of the pulmonary blood-gas barrier in elite athletes. Am J Respir Crit Care Med. 1997;155:1090-4.

20. Mascheroni D, Kolobow T, Fumagalli R, Moretti MP, Chen V, Buckhold D. Acute respiratory failure following pharmacologically induced hyperventilation: an experimental animal study. Intensive Care Med. 1988;15:8-14.

21. Schmidt UH, Hess DR. Does spontaneous breathing produce harm in patients with the acute respiratory distress syndrome? Respir Care. 2010;55:784-6.

22. Yoshida T, Uchiyama A, Matsuura N, Mashimo T, Fujino Y. Spontaneous breathing during lung-protective ventilation in an experimental acute lung injury model: high transpulmonary pressure associated with strong spontaneous breathing effort may worsen lung injury. Crit Care Med. 2012:40:1578-85.

23. Ouimet S, Kavanagh BP, Gottfried SB, Skrobik Y. Incidence, risk factors and consequences of ICU delirium. Intensive Care Med. 2007;33:66-73.

24. Hager DN, Dinglas VD, Subhas S, Rowden AM, Neufeld KJ, Bienvenu OJ, et al. Reducing deep sedation and delirium in acute lung injury patients: a quality improvement project. Crit Care Med. 2013;41:1435-42.

25. Latronico N, Fenzi F, Recupero D, Guarneri B, Tomelleri G, Tonin P, et al. Critical illness myopathy and neuropathy. Lancet. 1996;347:1579-82.

26. Schweickert WD, Pohlman MC, Pohlman AS, Nigos C, Pawlik AJ, Esbrook CL, et al. Early physical and occupational therapy in mechanically ventilated, critically ill patients: a randomised controlled trial. Lancet. 2009;373:1874-82.

27. Duffin J. Measuring the ventilatory response to hypoxia. J Physiol. 2007;584:285-93.

28. Kolobow T, Gattinoni L, Tomlinson TA, Pierce JE. Control of breathing using an extracorporeal membrane lung. Anesthesiology. 1977;46:138-41.

29. Phillipson EA, Duffin J, Cooper JD. Critical dependence of respiratory rhythmicity on metabolic CO2 load. J Appl Physiol. 1981:50:45-54

30. Trenchard D, Gardner D, Guz A. Role of pulmonary vagal afferent nerve fibres in the development of rapid shallow breathing in lung inflammation. Clin Sci. 1972:42:251-63.

31. Ho CY, Gu Q, Hong JL, Lee LY. Prostaglandin E(2) enhances chemical and mechanical sensitivities of pulmonary C fibers in the rat. Am J Respir Crit Care Med. 2000;162:528-33.

32. Lin S, Walker J, Xu L, Gozal D, Yu J. Behaviours of pulmonary sensory receptors during development of acute lung injury in the rabbit. Exp Physiol. 2007;92:749-55.

33. Yu J, Lin S, Zhang J, Otmishi P, Guardiola JJ. Airway nociceptors activated by pro-inflammatory cytokines. Respir Physiol Neurobiol. 2007;156:116-9.

34. Kubin L, Alheid GF, Zuperku EJ, McCrimmon DR. Central pathways of pulmonary and lower airway vagal afferents. J Appl Physiol. 2006;101:618-27.

35. Wright PE, Bernard GR. The role of airflow resistance in patients with the adult respiratory distress syndrome. Am Rev Respir Dis. 1989;139:1169-74.

36. Nuckton TJ, Alonso JA, Kallet RH, Daniel BM, Pittet JF, Eisner MD, et al. Pulmonary dead-space fraction as a risk factor for death in the acute respiratory distress syndrome. N Engl J Med. 2002;346:1281-6.

37. Pranikoff T, Hirschl RB, Remenapp R, Swaniker F, Bartlett RH. Venovenous extracorporeal life support via percutaneous cannulation in 94 patients. Chest. 1999;115:818-22.

38. Turner DA, Cheifetz IM, Rehder KJ, Williford WL, Bonadonna D, Banuelos SJ, et al. Active rehabilitation and physical therapy during extracorporeal membrane oxygenation while awaiting lung transplantation: a practical approach. Crit Care Med. 2011:39:2593-8.

39. MacLaren G, Combes A, Bartlett RH. Contemporary extracorporeal membrane oxygenation for adult respiratory failure: life support in the new era. Intensive Care Med. 2012;38:210-20.

40. Camboni D, Philipp A, Lubnow M, Bein T, Zausig Y, Hilker M, et al. Extracorporeal membrane oxygenation by single-vessel access in adults: advantages and limitations. ASAIO J. 2012:58:616-21.

41. de Bucourt M, Teichgraber UK. Image guided placement of extracorporeal life support through bi-caval dual lumen venovenous membrane oxygenation in an interventional radiology setting-initial experience. J Vasc Access. 2012;13:221-5

42. Javidfar J, Wang D, Zwischenberger JB, Costa J, Mongero L, Sonett J, et al. Insertion of bicaval dual lumen extracorporeal membrane oxygenation catheter with image guidance. ASAIO J. 2011:57:203-5.

43. Langer T, Vecchi V, Belenkiy SM, Cancio LC, Gattinoni L, Batchinsky Al. Pressure-guided positioning of bicaval dual-lumen catheters for venovenous extracorporeal gas exchange. Intensive Care Med. 2013;39:151-4. 
44. Rubino A, Vuylsteke A, Jenkins DP, Fowles JA, Hockings L, Valchanov K Direct complications of the Avalon bicaval dual-lumen cannula in respiratory extracorporeal membrane oxygenation (ECMO): single-center experience. Int J Artif Organs. 2014;37:741-7.

45. Tanaka D, Pitcher HT, Cavarocchi N, Hirose H. Migrated Avalon veno-venous extracorporeal membrane oxygenation cannula: how to adjust without interruption of flow. J Card Surg. 2015;30:865-8.

46. Spinelli E, Bartlett RH. Relationship between hemoglobin concentration and extracorporeal blood flow as determinants of oxygen delivery during venovenous extracorporeal membrane oxygenation: a mathematical model. ASAIO J. 2014;60:688-93.

47. Barnard M, Shukla A, Lovell T, Goldstone J. Esophageal-directed pressure support ventilation in normal volunteers. Chest. 1999;115:482-9.

48. Kiely DG, Cargill RI, Lipworth BJ. Effects of hypercapnia on hemodynamic, inotropic, lusitropic, and electrophysiologic indices in humans. Chest. 1996; 109:1215-21.

49. Langer T, Vecchi V, Belenkiy SM, Cannon JW, Chung KK, Cancio LC, et al. Extracorporeal gas exchange and spontaneous breathing for the treatment of acute respiratory distress syndrome: an alternative to mechanical ventilation? Crit Care Med. 2014;42:e211-20.

50. Tallman Jr RD, Marcolin R, Howie M, McDonald JS, Stafford T. Cardiopulmonary response to extracorporeal venous $\mathrm{CO} 2$ removal in awake spontaneously breathing dogs. J Appl Physiol (1985). 1986;61:516-22.

51. Field S, Kelly SM, Macklem PT. The oxygen cost of breathing in patients with cardiorespiratory disease. Am Rev Respir Dis. 1982;126:9-13.

52. Scano G, Innocenti-Bruni G, Stendardi L. Do obstructive and restrictive lung diseases share common underlying mechanisms of breathlessness? Respir Med. 2010;104:925-33.

53. Gattinoni L, lapichino G, Kolobow T. Hemodynamic, mechanical and renal effects during "apneic oxygenation" with extracorporeal carbon dioxide removal, at different levels of intrapulmonary pressure in lambs. Int J Artif Organs. 1979:2:249-53.

54. Pesenti A, Rossi N, Calori A, Foti G, Rossi GP. Effects of short-term oxygenation changes on acute lung injury patients undergoing pressure support ventilation. Chest. 1993;103:1185-9.

55. Benzing A, Mols G, Brieschal T, Geiger K. Hypoxic pulmonary vasoconstriction in nonventilated lung areas contributes to differences in hemodynamic and gas exchange responses to inhalation of nitric oxide. Anesthesiology. 1997:86:1254-61.

56. Morimont $\mathrm{P}$, Batchinsky A, Lambermont B. Update on the role of extracorporeal $\mathrm{CO}(2)$ removal as an adjunct to mechanical ventilation in ARDS. Crit Care. 2015;19:117.

57. Akoumianaki E, Maggiore SM, Valenza F, Bellani G, Jubran A, Loring SH, et al. The application of esophageal pressure measurement in patients with respiratory failure. Am J Respir Crit Care Med. 2014;189:520-31.

58. Toumpanakis D, Kastis GA, Zacharatos P, Sigala I, Michailidou T, Kouvela M, et al. Inspiratory resistive breathing induces acute lung injury. Am J Respir Crit Care Med. 2010;182:1129-36.

59. Hayes Jr D, Kukreja J, Tobias JD, Ballard HO, Hoopes CW. Ambulatory venovenous extracorporeal respiratory support as a bridge for cystic fibrosis patients to emergent lung transplantation. J Cyst Fibros. 2012;11:40-5.

60. Rehder KJ, Turner DA, Hartwig MG, Williford WL, Bonadonna D, Walczak Jr $\mathrm{RJ}$, et al. Active rehabilitation during extracorporeal membrane oxygenation as a bridge to lung transplantation. Respir Care. 2013;58:1291-8.

61. Fuehner T, Kuehn C, Hadem J, Wiesner O, Gottlieb J, Tudorache I, et al. Extracorporeal membrane oxygenation in awake patients as bridge to lung transplantation. Am J Respir Crit Care Med. 2012;185:763-8.

62. Crotti S, lotti GA, Lissoni A, Belliato M, Zanierato M, Chierichetti M, et al. Organ allocation waiting time during extracorporeal bridge to lung transplant affects outcomes. Chest. 2013;144:1018-25.

63. Mason DP, Thuita L, Nowicki ER, Murthy SC, Pettersson GB, Blackstone EH. Should lung transplantation be performed for patients on mechanical respiratory support? The US experience. J Thorac Cardiovasc Surg. 2010:139:765-73.

64. Schnell D, Timsit JF, Darmon M, Vesin A, Goldgran-Toledano D, Dumenil AS, et al. Noninvasive mechanical ventilation in acute respiratory failure: trends in use and outcomes. Intensive Care Med. 2014:40:582-91.

65. Abrams DC, Brenner K, Burkart KM, Agerstrand CL, Thomashow BM, Bacchetta $M$, et al. Pilot study of extracorporeal carbon dioxide removal to facilitate extubation and ambulation in exacerbations of chronic obstructive pulmonary disease. Ann Am Thorac Soc. 2013;10:307-14.
66. Burki NK, Mani RK, Herth FJ, Schmidt W, Teschler H, Bonin F, et al. A novel extracorporeal $\mathrm{CO}(2)$ removal system: results of a pilot study of hypercapnic respiratory failure in patients with COPD. Chest. 2013;143:678-86.

67. Del Sorbo L, Pisani L, Filippini C, Fanelli V, Fasano L, Terragni P, et al. Extracorporeal Co2 removal in hypercapnic patients at risk of noninvasive ventilation failure: a matched cohort study with historical control. Crit Care Med. 2015:43:120-7.

68. Kluge S, Braune SA, Engel M, Nierhaus A, Frings D, Ebelt $H$, et al. Avoiding invasive mechanical ventilation by extracorporeal carbon dioxide removal in patients failing noninvasive ventilation. Intensive Care Med. 2012;38:1632-9.

69. Roncon-Albuquerque Jr R, Carona G, Neves A, Miranda F, Castelo-Branco S, Oliveira $T$, et al. Venovenous extracorporeal CO2 removal for early extubation in COPD exacerbations requiring invasive mechanical ventilation. Intensive Care Med. 2014;40:1969-70.

70. Hoeper MM, Wiesner O, Hadem J, Wahl O, Suhling H, Duesberg C, et al. Extracorporeal membrane oxygenation instead of invasive mechanical ventilation in patients with acute respiratory distress syndrome. Intensive Care Med. 2013;39:2056-7.

71. Wiesner O, Hadem J, Sommer W, Kuhn C, Welte T, Hoeper MM. Extracorporeal membrane oxygenation in a nonintubated patient with acute respiratory distress syndrome. Eur Respir J. 2012;40:1296-8.

72. Olsson KM, Simon A, Strueber M, Hadem J, Wiesner O, Gottlieb J, et al. Extracorporeal membrane oxygenation in nonintubated patients as bridge to lung transplantation. Am J Transplant. 2010;10:2173-8.

73. Javidfar J, Brodie D, Iribarne A, Jurado J, Lavelle M, Brenner K, et al. Extracorporeal membrane oxygenation as a bridge to lung transplantation and recovery. J Thorac Cardiovasc Surg. 2012;144:716-21.

74. Hoopes CW, Kukreja J, Golden J, Davenport DL, Diaz-Guzman E, Zwischenberger JB. Extracorporeal membrane oxygenation as a bridge to pulmonary transplantation. J Thorac Cardiovasc Surg. 2013;145:862-7.

75. Lang G, Kim D, Aigner C, Matila J, Taghavi S, Jaksch P, et al. Awake extracorporeal membrane oxygenation bridging for pulmonary retransplantation provides comparable results to elective retransplantation. J Heart Lung Transplant. 2014;33:1264-72.

76. Mohite PN, Sabashnikov A, Reed A, Saez DG, Patil NP, Popov AF, et al. Extracorporeal life support in "awake" patients as a bridge to lung transplant. Thorac Cardiovasc Surg. 2015;63:699-705.

77. Inci I, Klinzing S, Schneiter D, Schuepbach RA, Kestenholz P, Hillinger S, et al. Outcome of extracorporeal membrane oxygenation as a bridge to lung transplantation: an institutional experience and literature review. Transplantation. 2015;99:1667-71. 